\title{
Concurrent Approach to Teaching Concurrent Design Engineering
}

\author{
Remon Pop-Iliev and Scott B. Nokleby \\ Faculty of Engineering and Applied Science \\ University of Ontario Institute of Technology \\ 2000 Simcoe Street North \\ Oshawa, ON L1H $7 K 4$ \\ CANADA \\ remon.pop-iliev@uoit.ca \\ scott.nokleby@uoit.ca
}

\begin{abstract}
By extending the rationale of concurrency into undergraduate engineering educational settings, this paper proposes an innovative approach to design engineering training and education, the essential objective of which is to achieve "the consideration of all downstream challenges which are likely to affect an engineering graduate's professional career at the earliest possible point in the future engineer's education." The goalof this approach is to ensure that engineering graduates embark on their industrial careers adequately prepared for dealing with the specifics of the workplace, i.e., to train them "to expect the unexpected". A second-year Concurrent Engineering and Design course taught at the University of Ontario Institute of Technology (UOIT) is utilized as an implementation example.
\end{abstract}

\section{Introduction}

Design engineering is the central focus of the engineering profession. The design engineering process encircles the complex engineering efforts involved in creating new ways of addressing customers' needs by using fresh approaches to launching new concepts and to engineering problem solving. Thus, innovation in design engineering is the principal engine of economic growth.

The economic, ecological and social challenges facing the world now and in the future require rapid implementation of radically new approaches to the product realization process, in which design engineering plays a crucial role. Therefore, a novel kind of design engineering education and training is necessary in order to graduate engineers who will be able to address efficiently and effectively the increasing challenges caused by economic uncertainty, constrained resources and stiff global competition. These challenges call for accelerated innovation, research, and development in the fields of engineering and applied science with a focus on the highest levels of achievement in design engineering, product development, management engineering, processing technology, and environmental stewardship.

Fully recognizing this fact, the Faculty of Engineering and Applied Science (FEAS) at UOIT has developed a design-intensive engineering curricula, the fundamental objective of which is to substantially contribute to improving Canada's capacity in design engineering.

Having been recently established, UOIT provides the ideal setting and unique opportunity for the creation, prompt adoption, and implementation of advanced and innovative practices in teaching design engineering, without having to go through the burden of modifying or abandoning traditional practices. Each student has a laptop equipped with a suite of software that facilitates the learning process regardless of time and location within the campus. The "web-centric" environment around which the University operates utilizes the latest technologies that support traditional face-to-face teaching while expanding Internet-based learning and collaborative learning. This environment offers opportunities for investigating innovative teaching and learning techniques based on these technologies that will not only enrich students' design engineering experience but could also serve as a focal point for multidisciplinary design engineering teams who will be instrumental in meeting effectively emerging needs for creating innovative products, processes, technologies and services.

Through incorporating specific strategies into the engineering curriculum and intensive collaboration with industry, the authors of this paper are strongly committed to extend and promote the most advanced concepts of design engineering and innovation into UOIT's general engineering educational setting and beyond. This paper focuses on demonstrating a fraction of these efforts. 


\section{Background}

Near the very end of the previous century, voices from the Canadian automotive industry strongly suggested that new Canadian engineering graduates do not possess the skills and knowledge needed within the sector. Therefore, Canadian automakers used to recruit automotive design engineers in Europe, whereas at the same time, U.S.-based companies demonstrated willingness to hire new Canadian graduates and then train them with the necessary skills [1].

On the other hand, the open literature published at the approximately same time indicated that, in the current practice, higher undergraduate engineering subjects are taught to significant depth and complexity. However, design engineering is commonly taught in a relatively isolated manner so that integration of these subject areas into a coherent thread is seldom considered. The reasons for this usually include lack of resources, ignorance of novel technologies, or an aging academic environment [2].

Therefore, the majority of Canadian engineering graduates at the dawn of the 21 century were generally perceived as mainly demonstrating satisfactory analysis abilities, but lacking competence in the areas of synthesis, design, and innovation. These critiques raised clear concerns regarding the engineering curricula that required quick fixes at the majority of Canadian universities, especially at those that have not devoted adequate coverage to design and innovation and to the integration of these areas into design-oriented curricula.

In this context, a recent publication of the Canadian Academy of Engineering reported that employers in Canada have generally expressed satisfaction with the technical capabilities of engineering graduates, whereas they are much less content with the skills in certain non-technical areas such as communication ability, economics, leadership, teamwork and management [3].

In addition, a very recently published analysis identified five Canadian universities that provided unique innovative engineering programs and therefore "got top marks for innovation in engineering education", thereby moving the profession forward [4]. The successes of these five universities certainly deserve acknowledgment and represent a very important step towards developing engineering graduates for a competitive global marketplace. However, the fact that only five such universities have been distinguished implies that the remaining majority of Canadian universities running engineering schools are still being perceived as providing a so-called "run-of-the-mill" type of engineering education. Consequently, it remains unclear whether these five institutions have improved the public perception on engineering education, or the majority of newly graduated Canadian engineers would still be generally perceived as "run-of themill" engineering graduates [5].

In a deliberate effort, UOIT's FEAS undertook energetic actions to properly address the apparent common deficiencies of existing engineering curricula, right from the time of its constitution and the conceiving of its design strategy. The core of these efforts included the dedication for introducing and propagating distinctive educational approaches aimed at training competent engineers in programs that are free of obsolescence and that have design engineering as a central pillar.

\section{The Concept of Concurrency}

In industrial settings, design engineering errors almost always necessitate significant engineering fixes that dramatically augment product development and realization costs, thereby usually rendering products profitless. The concurrent engineering approach, often defined as "the consideration of all downstream activities which are likely to affect the product's life cycle at the product's design stage", is widely regarded as the most efficient strategy for early suppression of design-related anomalies and getting the product right the first time. Regrettably, this does not fix the most probable root cause for design engineering errors: the relative incompetence of design engineering teams. This incompetence perhaps could be attributed to obsolete, inadequate, and/or poorly designed engineering curricula.

Therefore, it seems that a substantial culture change in teaching design engineering appears to be an immediate necessity. While it is difficult to predict exactly which skills future engineers will need, this change would have to include several innovative elements that will be educating well-rounded graduates that would be able to "expect the unexpected."

In this context, the authors strongly believe that the essential rationale of concurrent engineering should be introduced into undergraduate engineering educational settings as an innovative approach to design engineering training and education. This approach is essentially striving to achieve "the consideration of all downstream challenges which are likely to affect an engineering graduate's professional career at the earliest possible point in the future engineer's education". It is intended to provide a thorough and simultaneous training in understanding product desirability, technological feasibility, and business viability while aiming towards developing a new profile of a "hybrid" 
engineering professional having sound technological knowledge, creative design skills, and a clear understanding of business that will be capable of balancing user-focused design with the profitable application of novel technologies.

On the other hand, successfully getting customer-focused innovative designs to the market within the shortest possible lead times has been of paramount importance for company survival. Consequently, today's companies that are making the greatest profits are the innovative ones, not the low cost ones. Although companies normally use design innovation to improve on existing products, sometimes these efforts evolve into creating a completely new class of products that begin to dominate an entire market segment. Therefore, the concurrent approach to teaching design engineering is strategically aimed towards igniting engineering curiosity and finding new methodologies to focus innovation efforts so they foster innovative design engineering ideas and meaningfully integrate these ideas into the engineering curricula.

Being founded on regarding design engineering as the coherent thread that correlates the various engineering and scientific subjects taught within undergraduate engineering programs, the concurrent approach to engineering education also includes the delivery of integrated courses. These include courses that take basic engineering concepts and connect them to related concepts in other subject areas to provide superior-learning project-based experiences for students and helps to produce engineers who better understand "the big picture."

\section{The Course: ENGR 2310U}

The engineering curricula at FEAS have been carefully designed with the view that team-based design projects improve motivation and engagement in achieving learning objectives. Therefore, it is and it will be common in all design engineering-based courses at FEAS to have the integration of all the topics covered throughout the course achieved through major team-based design and CAD modeling projects with increasing complexity. Students will be given the opportunity to participate by working in groups of 3 to 5 on one of these topics over the duration of the semester.

Concurrent Engineering and Design (ENGR 2310U) was developed and introduced as a first-term second-year engineering course at UOIT's FEAS. This course was initially offered in the fall of 2004 for the very first Manufacturing Engineering class with an enrolment of 84 students. It will be utilized in this paper to illustrate how the proposed concurrent approach to design engineering education and training can be implemented. Due to the subsequent creation of new engineering programs at FEAS, it has also been introduced into the course calendars of the Mechanical Engineering program that was inaugurated in the fall of 2004 as well as the Automotive Engineering program that will be inaugurated in the fall of 2005.

Course Description. ENGR $2310 \mathrm{U}$ covers the modern integrated product development process by introducing a set of analytical, quantitative and computational methods and tools to improve integrated product / service / process design and related engineering management and IT aspects. Unlike the traditional product development approach, concurrent (simultaneous) engineering and design reunites technical and non-technical disciplines and brings forward a philosophy of cross-functional cooperation in order to create products which meet pre-determined objectives, and are better, less expensive, and more quickly brought to market. It is a process in which appropriate disciplines are committed to work interactively to analyze market and customer requirements in order to improve the end-to-end process by which products are conceived, designed, manufactured, assembled, sold to the customer, serviced, and finally disposed. The concept of design is presented via a combination of case-studies, brainstorming, design analysis, design synthesis topical sessions, etc. Creativity methods, design for manufacturing, design for assembly, design for cost, design for quality, life cycle design, reverse engineering, robust design, and rapid prototyping are addressed. Teamwork and communication skills are strongly encouraged and developed through group assignments. Throughout the term, students are assigned four biweekly individual problem sets, a group case study, and two group design projects.

Textbook Requirements. Students are required to acquire one textbook [6] for supporting the lecture topics covered in the course and another lab manual [7] to support the laboratory work.

Teaching Method. This one-semester course is delivered by a combination of web-centric supported classroom lectures using WebCT and computer laboratory project work ( 3 hours of lectures and 2 hours of labs per week). Lectures are designed to ensure that students understand the basic concepts of concurrent engineering and design. Lecture notes and assignments are made available to students in Microsoft PowerPoint $\AA$, Microsoft Word $\AA$, or Adobe Acrobat ${ }^{\circledR}$ format. Strong emphasis is given to teamwork. The laboratories provide exposure to an advanced level of hands-on application of the latest version of SolidWorks ${ }^{\circledR}$ solid modeling software and CAD exercises. Practical work assigned to students 
helps students to achieve the learning outcomes. Project management software such as Microsoft Project is also briefly covered. The comprehensive eLearning package the textbook is supported with comprising two web-browser readable open source 3D interactive multimedia contents and real-world research and industrial case studies on CD-ROMs is also utilized to help achieve the learning outcomes.

Expected Learning Outcomes. Students who successfully complete the course should have reliably demonstrated the ability to implement several wellestablished methods such as: (i) quality function deployment, (ii) requirements analysis, (iii) collaborative concurrent engineering (and service) process modeling, (iv) process failure mode and risk analysis methods (Poka -Yoke, Kanzei and others), (v) rapid prototyping methods, (vi) use of a computer-based design and drafting program in the solution of individual and group engineering design projects, (vii) use of a spreadsheet program to perform calculations in at least one aspect of an engineering design, and (viii) demonstrate the use of project management software in the planning, reporting and control of group case studies and group design projects. The hands-on practice in the use of computer-aided design solid modeling tools will give students confidence in the use of these tools in their subsequent courses and for employment.

\section{Marking Scheme.}

1. Four Biweekly Assignments $(4 \times 2 \%) \quad 8 \%$

2. Group (4-5 students) Case Study 2\%

3. Mid-term Exam 15\%

4. Final Exam $\quad 30 \%$

5. Two Group Design Projects $(15 \%+30 \%) \quad 45 \%$

\section{Applying the Concept of Concurrency}

Embedding innovation in design engineering training while ensuring that the educative design engineering cases are industry driven and realistic is used extensively within this concept as a practical means for overcoming the inherent difficulty of teaching creativity, strategic thinking, and innovation in design engineering education.

It is the hands-on project-based training on how to arrive at solutions that adds significant value and excitement to the learning experiences of engineering students. In this context, the two group design projects introduced in ENGR 2310U have been deliberately valued at almost half of the weight of the total course mark, so they hold the most prominent place within the entire course. A prerequisite for enrolment in ENGR 2310U is the successful completion of Engineering Graphics and Design, ENGR 3200U, a first-year course that innovatively encompasses design engineering topics and a major group project undertaking. Interested readers are encouraged to see [8] for more details about ENGR 3200U.

Because when teaching design engineering in large classes it is rather difficult to focus on achievement standards while simultaneously creating an exciting and fun instructional environment, the design engineering projects guidance for ENGR $2310 \mathrm{U}$ is organized in small classes, not larger than 30 learners. These are further subdivided into project teams consisting of 3 to 5 people suitable for full implementation of the project-based approach to design engineering training.

Although traditional lecture-based teaching delivers the information, one learns through the process of constructing some type of artefact. To foster and emphasize the hands-on component of the training in an innovative way, each group of students has been provided with a Meccano ${ }^{\circledR} 50$ Model Set design kit that assures all groups with equal opportunities for project-related prototype building and visualization.

By deliberate exposure of students to extensive use of state-of-the-art multi-media technology and other design engineering CAD and analysis tools, the students are provided the opportunity to "work virtually" as future members of virtual corporate design teams that use collaborative networks to design and develop products innovatively.

The principal goal of this concept is to design and implement a virtual design-project environment for learning in a less traditional setting that simulates a real-life workplace environment and fosters collaborative learning. This latter point is accomplished by allowing students to design and build virtual objects collaboratively with other students "located at a distance", thereby achieving improvements in their collaborative and cognitive skills, and ultimately their employability.

Logistics of Design Groups. The ENGR 2310U class was initially divided into groups of 3 to 5 people while honouring students' individual preference for forming particular teams willing to work together. Then, the groups were assigned random numbers for identification purposes and the names of the respective constituents of each group were posted on the WebCT site dedicated to the course. Each group of students was provided a Meccano ${ }^{\circledR} 50$ Model Set and a suitable aluminium briefcase with corresponding compartments for enhanced mobility and convenience in handling the design kit. In a deliberate attempt to mimic the interpersonal realities attributed to real workplace design teams, the students were advised that, except in extraordinary circumstances, fluctuation of the members of the groups during the duration of the 
term would not be permitted. Thereby, like in a reallife workplace scenario, students will have to learn to collaborate in a decent fashion even with people they would rather wish to avoid.

Fairness and Uniformity Policy. Making full usage of the provided Meccano ${ }^{\circledR} 50$ Model Set during the work on the projects in ENGR 2310U was obligatory. The use of additional parts or elements must be justified and previously approved. The total value of additional elements used per project cannot be over \$20 per group. Equal marks were assigned to each legitimate group member.

Timing. The first group design project within ENGR 2310U was intentionally assigned to the students during the fourth week of the term and was due in four weeks. This timing strategy allowed the students to grasp the fundamental principles of concurrent engineering during the lecture contact hours over the initial three weeks of the term. Thereby, they also had a chance to first review the basic SolidWorks ${ }^{\circledR}$ skills they had previously acquired in ENGR 3200U and then enhance their proficiency in mastering this CAD package by attending more advanced topics during the regularly scheduled laboratory sessions. The second group design project was assigned during the eighth week of the term and was due in five weeks, i.e., at the end of the term.

\section{Group Design Project \#1}

Title. "Design of a Free Choice Type of Vehicle Based on a Common Platform Concept Supporting Interchangeable Vehicle Bodies". Note: Assemblies having larger numbers of parts would be preferred for this design project. Total project mark: Max. 15\%.

Pedagogical Elements. In essence, this project was developed with three fundamental pedagogical elements in mind.

First, it was intended to familiarize the students with the General Motors-originated autonomy concept that is based on a universal "skateboard-like" platform, which is nothing but a mass-produced sixinch chassis that would allow a variety of body types to be economically built and added onto it.

Second, this project was meant to provide practical training in applying concurrent engineering principles while fostering interaction among various student design groups in the class by requiring collaboration with respect to a common design task. In this context, the design of the common platform was expected to be first negotiated and decided upon while working in "super groups" that included 3 to 4 small design groups consisting of 3 to 5 people each.
Overall single group work was not allowed in this initial segment of the project.

Third, once the detailed design of the common platform was decided upon by collaborating on a higher level in "super groups", each individual small design group was supposed to continue to work on their own to complete the rest of the project requirements.

Requirements. Student design groups were expected to design, appropriately document, and build a model of a vehicle body that would fit on the previously commonly designed platform belonging to the corresponding "super group", for which they were also required to provide complete design engineering documentation and a model, based on the Meccano ${ }^{\circledR} 50$ Model Set. In addition, each student group was required to perform a five minutes long inclass PowerPoint ${ }^{\circledR}$ supported presentation and prototype demonstration of their work. In general, student design groups were required to submit both a hard copy and a CD containing a logbook and complete engineering documentation in SolidWorks ${ }^{\circledR}$ that would be necessary for manufacturing their vehicle including the common platform at a remote location, as well as the PowerPoint ${ }^{\circledR}$ presentation with the presentation script.

\section{Marking scheme.}

A) Project mark is Max. 10\% consisting of: 1. Logbook (up to 5 pages) indicating and neatly describing dates of group meetings, interaction details, addressing issues such as brainstorming, concept generation, freehand sketches, communication via e-mail, design decisions brought with reasons and rationale implemented. Max. 1\% 2. Preparation of a full functioning prototype made using the design kit. Max. 1\% 3. 3D full assembly drawing (a respective file that demonstrates movable parts). Max 2\% 4. 3D engineering drawings of all designed subassemblies, components, and parts including respective multiview drawings of parts having all necessary dimensions and tolerances and BOMs as appropriate.

Max. 6\%

B.) Presentation mark is Max. 5\% consisting of:

1. Complying with time limits. Max. $1 \%$

2. Clarity and professionalism. Max. $1 \%$

3. Quality of technical content. Max. $1 \%$

4. Quality of visuals. Max. 1\%

5. Prototype demonstration. Max. 1\%

Results. Figures 1 to 6 depict typical representatives of final models made using the Meccano ${ }^{\circledR} 50$ Model Set of various vehicle designs mounted on various commonly accepted platforms presented by the students in Group Design Project \#1. 


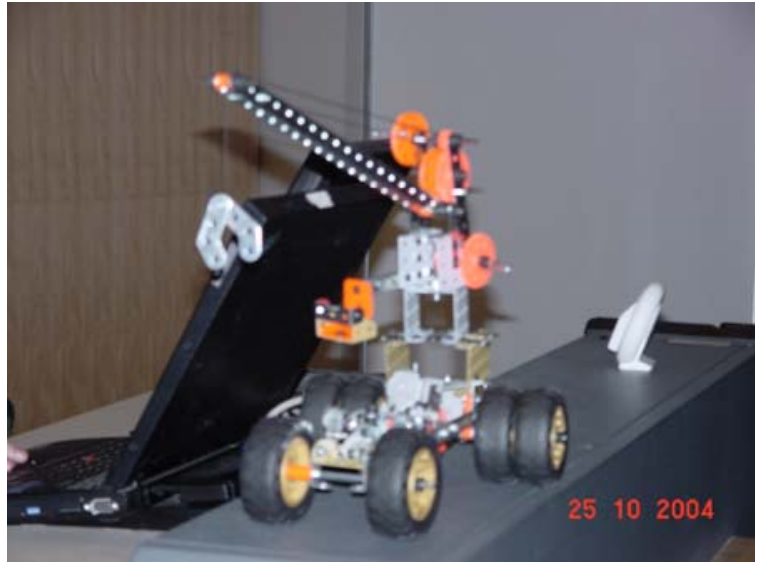

Figure 1. Group members: Theodora Biney, Pierre Hinse, Samveg Saxena, Matthew Van Wieringen, and Kayla Viegas

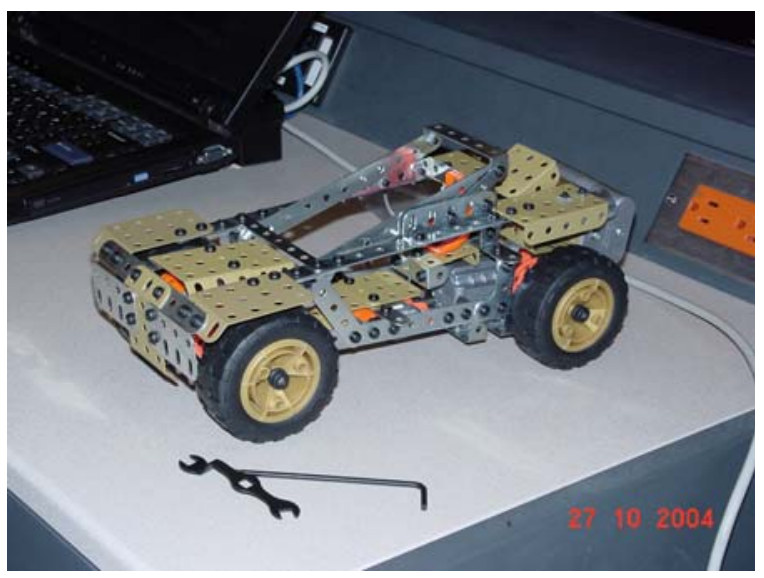

Figure 3. Group members: Paul Aquino, Jatin Patel, lan Rampergass, Carlos Rodriguez, and Misaghollah Tabrizi

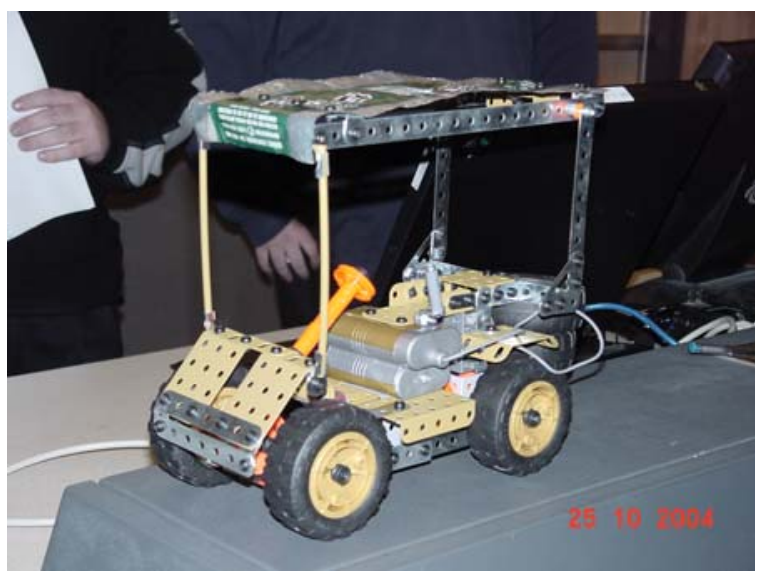

Figure 5. Group members: Steven Bemis, Gregory Campbell, Jonathan Herstead, and Brian Riess

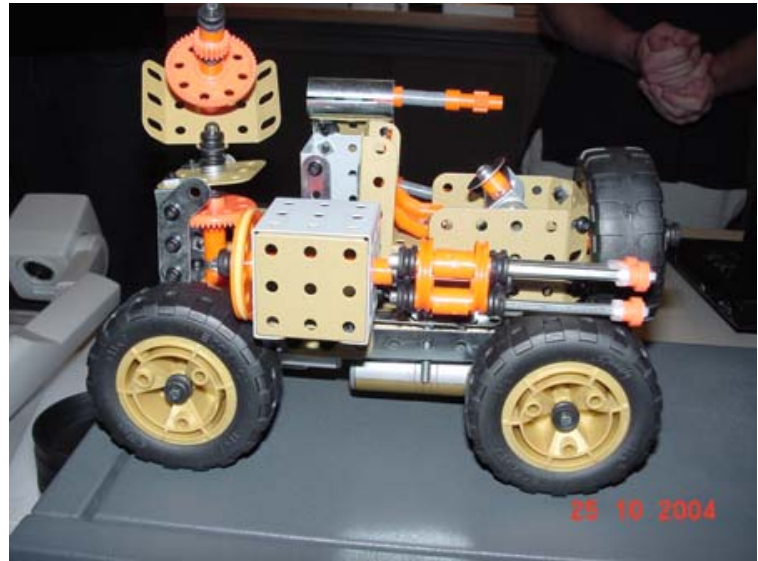

Figure 2. Group members: Peter Budd, Kyle Dabrowski, Kyle Mullin, and Jason Parise

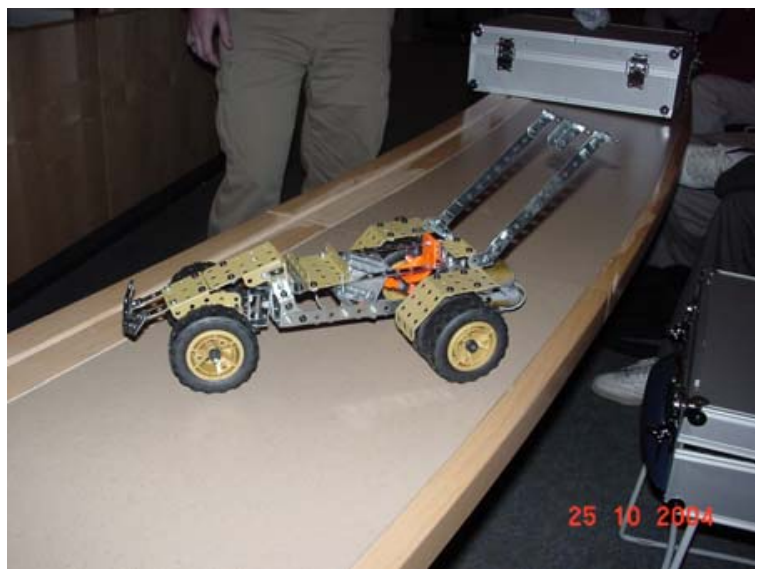

Figure 4. Group members: Marco Antonelli, Mark Bernacki, Thomas Bohan, Michael Frejek, and Darrin Willis

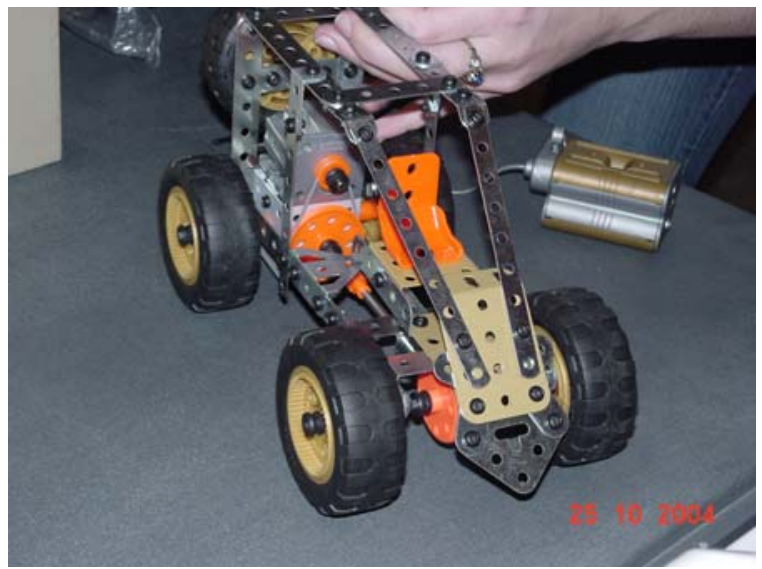

Figure 6. Group members: Jeff Bertrand, Kimberly Christian, William Hockings, Dmitry Koupriyanov, and Michael Manson 


\section{Group Design Project \#2}

Title. "Design of a Bi-Axial Mold Rotating Mechanism for Single-Charge Fabrication of Integral-Skin Polyolefin Foams". Note: Assemblies providing better design and technical/functionality merits would be preferred for this design project, regardless of the number of parts. Total project mark: Max. 30\%.

Problem Statement. After a thorough overview of the single-charge integral-skin rotational foam molding process of polyolefins had been presented to the students and a research-related corresponding experimental setup had been described, it was concluded that: uneven skin thickness was obtained because of the uni-axial nature of the experimental equipment used.

Suggested Probable Solution. A bi-axial experimental rotational molding apparatus would be necessary to obtain moldings with even skin thickness.

Pedagogical Elements. This project was developed with three fundamental pedagogical elements in mind.

First, it was intended to familiarize the students with an innovative rotational molding-based process for fabricating plastic foams and certain equipmentdesign related difficulties in developing optimal processing strategies.

Second, this project was meant to provide practical training in applying concurrent engineering principles in solving real-life industrially-related problems.

Third, since this project was much more involved than the first one, it provided the students with a unique opportunity to design processing equipment and obtain the necessary skills for preparing a full-size detailed engineering project report.

Requirements. Student design groups were expected to design, document, develop, build and demonstrate a working prototype using the Meccano ${ }^{\circledR} 50$ design kit on which a mold for fabrication of plastic parts (represented by a full unopened pop can of regular size) would be mounted and by which it would be rotated bi-axially around two perpendicular axis for at least one minute.

A professional-quality Design Engineering Project Report that consisted of the following components was expected:

(i) critical review of related relevant patent and research literature.

Use of appropriate project table of contents and format including a "literature survey" and "patent survey" (http://ep.espacenet.com) of existing similar mechanisms and analysis of their advantages and disadvantages and the references used.

Suggested link for guidance in report writing: http://www.ecf.toronto.edu/ writing/handbook.html.

(ii) documented brainstorming and feasible innovative design concepts generation using freehand sketching,

(iii) documented design evaluation and best innovative concept selection based on optimal designs that allow the production of more robust products with higher quality and reduced costs by implementing House of Quality, Design for Manufacture, Design for Assembly, Design for Cost, and/or Design for Environment principles/criteria,

(iv) actual preliminary design of the product using SolidWorks ${ }^{\circledR}$,

(v) virtual functionality prototyping using available simulation and engineering analysis tools,

(vi) documented plan for assembly and actual manufacture/assembly of a functional prototype using the most appropriate in-house tools and techniques,

(vii) documented prototype performance critical analysis, robustness testing, and suggestions for improvements, and

(viii) implementation of suggested physical improvements on prototype and final product design documentation generation.

In addition, each student group was required to perform a five minutes long in-class PowerPoint ${ }^{\circledR}$ supported presentation and prototype demonstration of their work.

Submission Requirements. Maximum of 30 pages of project text (1.5 spaced, font Time New Roman, size 12) excluding drawings (the number of drawings is not limited in any way) and a CD (or CDs) with its electronic version including all relevant SolidWorks ${ }^{\circledR} \quad$ files. Complete engineering documentation in SolidWorks ${ }^{\circledR}$ that would be necessary for manufacturing the bi-axially rotating mechanism at a remote location. A hard copy of the PowerPoint ${ }^{\circledR}$ presentation and the presentation script and a $\mathrm{CD}$ containing the PowerPoint ${ }^{\circledR}$ presentation, and script; (should be the same CD as above). The overall project would be marked for: completeness, originality, technical merits, clarity, quality of engineering drawings and manual, and feasibility of proposed design concept.

\section{Marking scheme.}

A) Project mark is Max. $25 \%$ consisting of: 1. Project report write-up including a logbook describing dates of group meetings, interaction details, literature and patent survey, addressing issues such as concept generation, freehand sketches, communication via e-mail, etc., design decisions brought with reasons and rationale implemented, 
design description, and owner's and assembly manual.

Max. 10\%

2. Preparation of a full functioning prototype made using the Meccano® 50 design kit. Max. 5\% 3. 3D full assembly drawing of the prototype (a respective file that demonstrates movable parts), 3D drawings of all subassemblies, components, and parts including respective multiview drawings of parts having all necessary dimensions and tolerances and BOMs as appropriate.

Max. $10 \%$

B.) Presentation mark is Max. 5\% consisting of:

1. Complying with time limits. Max. $1 \%$

2. Clarity and professionalism. Max. $1 \%$

3. Quality of technical content. Max. $1 \%$

4. Quality of visuals. Max. $1 \%$

5. Prototype demonstration. Max. 1\%

Results. Figures 7 to 12 depict typical representatives of final models made by using the Meccano ${ }^{\circledR} 50$ Model Set of various biaxial rotational molding setup designs presented by the students in Group Design Project \#2.

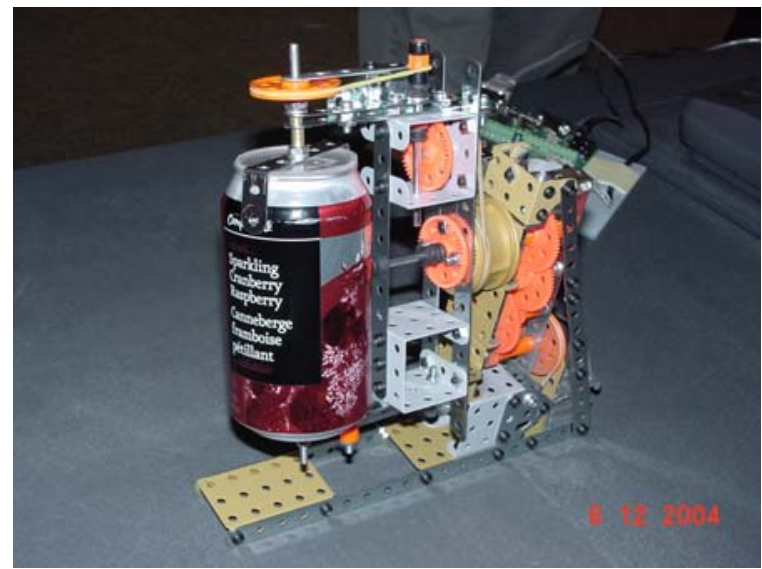

Figure 7. Group members: Theodora Biney, Pierre Hinse, Samveg Saxena, Matthew Van Wieringen, and Kayla Viegas

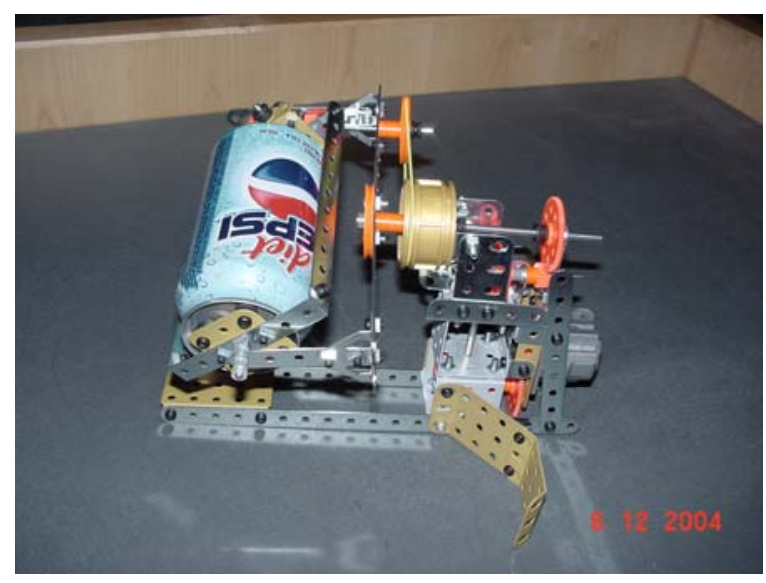

Figure 9. Group members: Zak Dennis, Leo Fortey, and Adam Kraehling

\section{Student Feedback and Successes}

"Concurrent engineering was by far the most enjoyable and the most practical course aiding me in my summer internships at General Motors. Looking forward to more of your courses in the fall!"

"Thanks for the great course.

We had a lot of fun"

"I would like to thank you for a great semester, and that I enjoyed being part of your class."

A five-member design team from the class was selected as one of five finalists in the 2004 Javelin SolidWorks ${ }^{\circledR}$ "Cool Design" Contest with their design of a common-platform-based off-road vehicle.

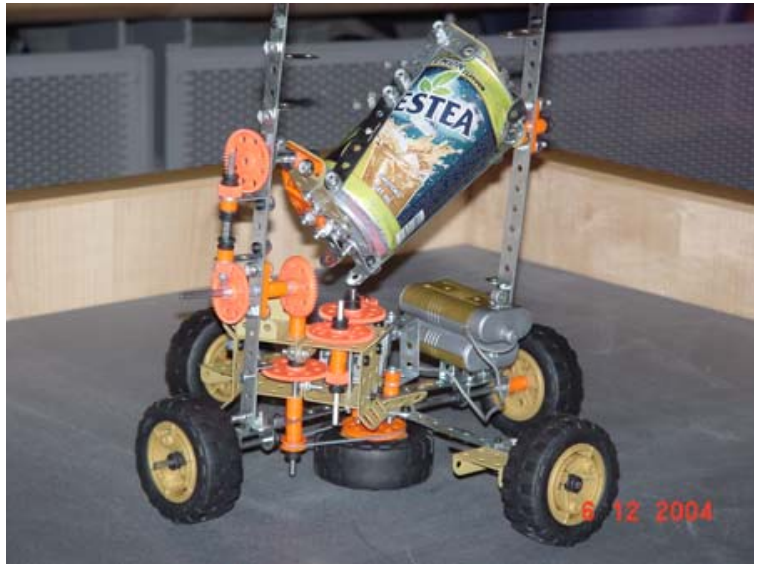

Figure 8. Group members: Marco Antonelli, Mark Bernacki, Thomas Bohan, Michael Frejek, and Darrin Willis

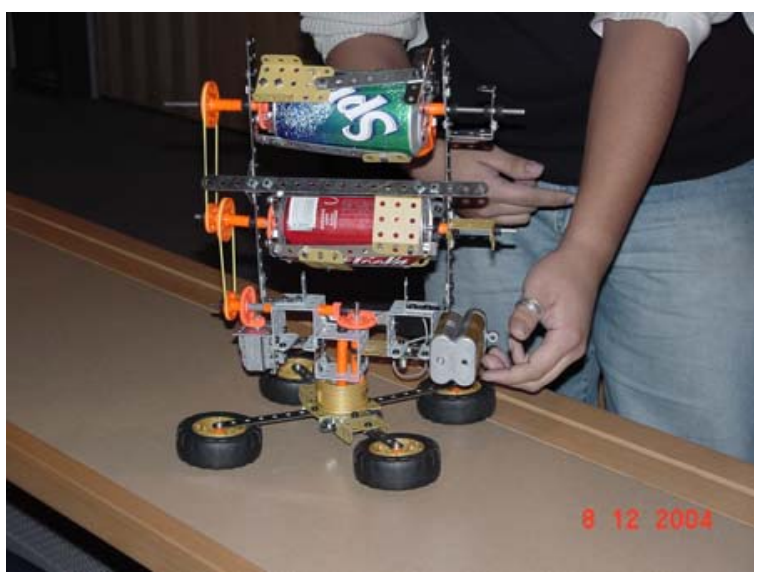

Figure 10. Group members: Caroline Chow, Damon Dastgiri, Jason Luckwell, John Miranda, Delish Sathianathan 


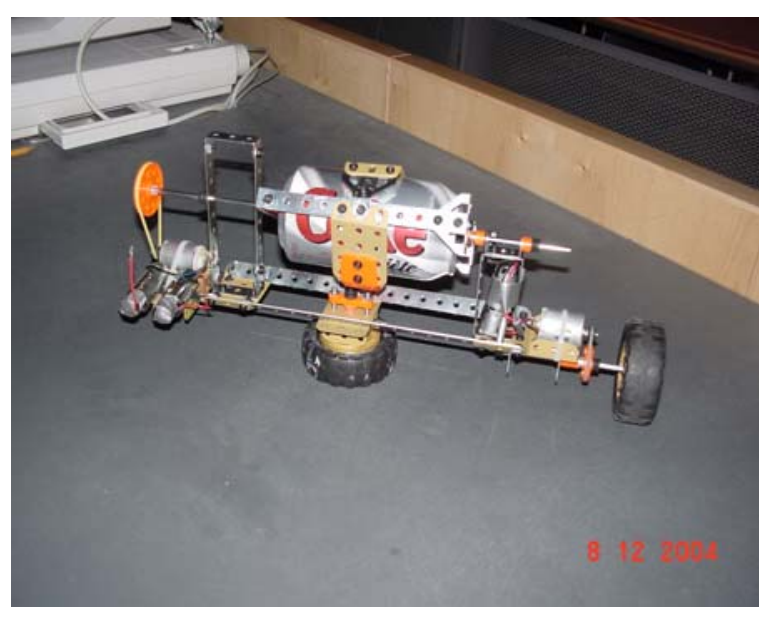

Figure 11. Group members: Sobia Akhtar, Frances Awachie, Akshay Deshpande, Stephen Forde, and Ahad Haseen

More recently, another four-member team from this second-year class successfully competed and achieved 5th place (unofficially) in the Senior Team Design category at the Ontario Engineering Competition that took place at the University of Waterloo in February 2005.

\section{Summary}

The national need for changes in the way that design engineers are generally educated has been well established. Since one of the most common approaches to improving engineering student learning is by attempting to improve engineering teaching, the development of innovative concepts and methods for teaching engineering design to undergraduate engineering students will remain a permanent goal and a critical element of the doctrine. Through an example of a Concurrent Engineering and design second-year engineering course, it was demonstrated that the concept of concurrent project-based learning and training through an increased integration of design engineering topics into engineering curricula has been successfully implemented at UOIT. In particular, the innovative introduction of Meccano 50 Model Sets as design kits provided an equal starting point to all student design groups in responding to design challenges while having to combine a limited number of predetermined parts and proved to have had strong impact on improving their visualisation and prototype building skills. On the other hand, exposing student groups to performing in class presentations with increasing difficulty three times during the term (a case study and two project presentations) proved to be beneficial for improving

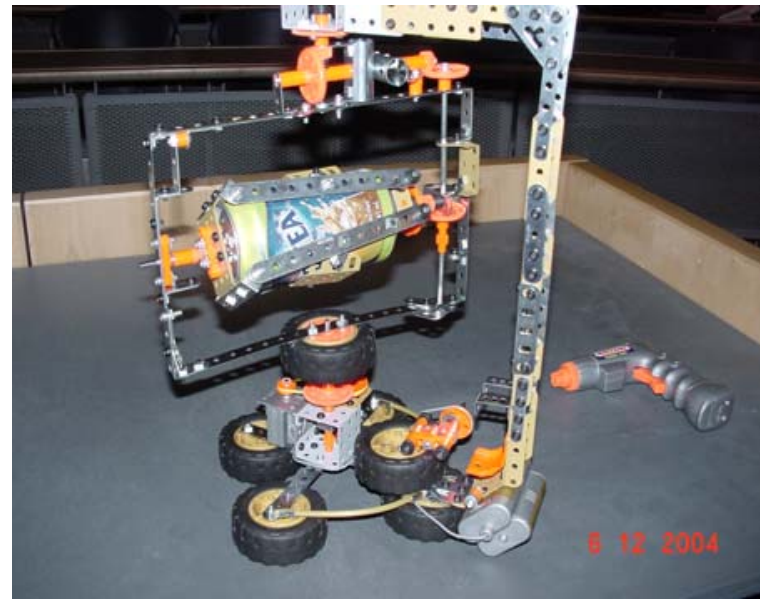

Figure 12. Group members: Peter Budd, Kyle Dabrowski, Kyle Mullin, and Jason Parise

their organization, presentation and time management skills. Overall, working successfully in teams on design projects while implementing concurrent engineering principles proved to be particularly beneficial for gaining workplace-like exposure and invaluable experience.

\section{Acknowledgements}

The authors want to express their gratitude to the UOIT students that allowed the publishing of their project work in this paper. These include: Theodora Biney, Pierre Hinse, Samveg Saxena, Matthew Van Wieringen, Kayla Viegas, Peter Budd, Kyle Dabrowski, Kyle Mullin, Jason Parise, Paul Aquino, Jatin Patel, Ian Rampergass, Carlos Rodriguez, Misaghollah Tabrizi, Marco Antonelli, Mark Bernacki, Thomas Bohan, Michael Frejek, Darrin Willis, Steven Bemis, Gregory Campbell, Jonathan Herstead, Brian Riess, Jeff Bertrand, Kimberly Christian, William Hockings, Dmitry Koupriyanov, Michael Manson, Zak Dennis, Leo Fortey, Adam Kraehling, Caroline Chow, Damon Dastgiri, Jason Luckwell, John Miranda, Delish Sathianathan Sobia Akhtar, Frances Awachie, Akshay Deshpande, Stephen Forde, and Ahad Haseen.

\section{References}

[1] P.R. Frise, "Trouble on the Shop Floor", PEO, Engineering Dimensions, pp. 26-29, Sept./Oct. (1999)

[2] B. Parkinson, P. Hudson and R. Senior, "A Virtual Environment for Concurrent Engineering using 
Artificial Intelligent Techniques", University of Hertfordshire, Hatfield, United Kingdom (2000)

[3] G. Slemon, "Assuring Competence in the Canadian Engineering Profession", Canadian Academy of Engineering (2003)

[4] K. Hawthorne, "Head of the Class", PEO, Engineering Dimensions, pp. 46-50, May/June (2005)

[5] J. Coombes, "Focused on the Future", PEO, Engineering Dimensions, pp. 6, May/June (2005)

[6] P.G. Ranky "An Introduction to Concurrent/ Simultaneous Engineering (Methods, Tools \& Case Studies)", CIMware USA Inc., ISBN 1872631320 (includes two interactive multimedia CD-ROMs)

[7] David C. Planchard and Marie P. Planchard, “Assembly Modeling with SolidWorks 2004" SDC Publications, Schroff Development Corporation, ISBN 1-58503-170-4

[8] S.B. Nokleby and R. Pop-Iliev, "A Design Challenge-Incorporating Design into the First Year Engineering Curriculum", The Second CDEN International Conference on Design Education, Innovation, and Practice, Kananaskis, Alberta, Canada, July 18-20, 2005 